\title{
Allograft Transplantation and Reconstruction of Bones after Malignant Tumor Resections.
}

\author{
Rezeart Dalipi *, Ilir Hasani, Milan Samardziski, Danica Popovska, \\ Simona Karapandzevska, Kornelija Gjorgjieska
}

Received: 01 December 2021 / Accepted: 28 December 2021 / Published online: 20 January 2022

This article is published with open access at https://journal.astes.org.al

(C) The author(s) 2022. \& Copyright (C) 2022, the Albanian Society for Trauma and Emergency Surgery

(c) The Albanian Journal of Trauma and Emergency Surgery is an Open Access Journal. All articles are distributed under the terms of the Creative Commons Attribution Non-Commercial License: http://creativecommons.org/licenses/by-nc/4.0/) which permits unrestricted non-commercial use, distribution, and reproduction in any medium provided the original work is properly cited.

\begin{abstract}
Reconstruction surgery after the excision of musculoskeletal tumors has advanced greatly in the last few decades. After resection of a large piece of bone, limb reconstruction (when is necessary) can be easily achieved with mechanical reconstruction with metallic prosthesis, or biological reconstruction with bone. The use of bone in reconstructive orthopedic surgery is to repair skeletal defects and accelerate bone healing. Bone grafts can be used to achieve this. Those can be allografts and autografts.

The standard in bone grafting consists of tissue harvested from the patient, autograft, usually from the iliac crest or distal femur and tibia. Allografts are taken from donors or cadavers and they serve as alternatives to autograft in bone reconstruction. In our case, the patients were treated with wide resection of the bone segment. The defect was reconstructed with intercalary bone and osteosynthesis was made with locking plates. A cadaveric graft was used. Autogenous bone is generally used as an optimal graft because it integrates faster and with fewer complications. Allogenous bone can carry the risk of viral infection for the recipient. Anyhow, allografts can serve as the only therapeutic options, besides endoprosthesis devices for large size reconstruction.

Keywords: allograft, transplantation, bony reconstruction, cadaveric, donor, metallic prosthesis;
\end{abstract}

\section{Introduction:}

With the latest development of neoadjuvant chemotherapy, radiotherapy and targeted therapy in the clinical treatment of malignant bony tumors, limb salvage surgery has become the most important surgical method for malignant bone tumors.

Limb salvage surgery includes two key techniques: radical resection of tumors and effective reconstruction of bone defects.[1]

The reconstruction of a large bony defect, especially after tumor resection still remains a fundamental challenge

Original article, no submission or publication in advance or in parallel

\section{* Corresponding author:}

Rezeart Dalipi MD

$\triangle$ arti_410@yahoo.com

University Clinic for Toariluc, Skopje, Republic of North MACEDONIA for an orthopedic surgeon. That requires an additional treatment with bone graft materials in order to restore the preexisting function. [2]

A successful bone augmentation should include an osteoconductive and osteo-inductive stimulus, should provide sufficient initial mechanical stability, and should enable osteogenesis, Osseo-integration and proper vascularity. [3]

The use of bone in reconstructive orthopedics is to repair the skeletal defect and accelerate bone healing. Bone grafts serve a combined mechanical and biologic function. [4]

After resection of a large piece of bone, reconstruction of the limb when it is needed, can be achieved with metallic implants, such as prosthesis, or with biological reconstruction with bone. [6]

We present three cases with malignant or aggressive bone tumors treated surgically with wide resection of the bone tumor and reconstruction of the bone defect with frozen cadaveric allograft. [7] 


\section{Case Reports.}

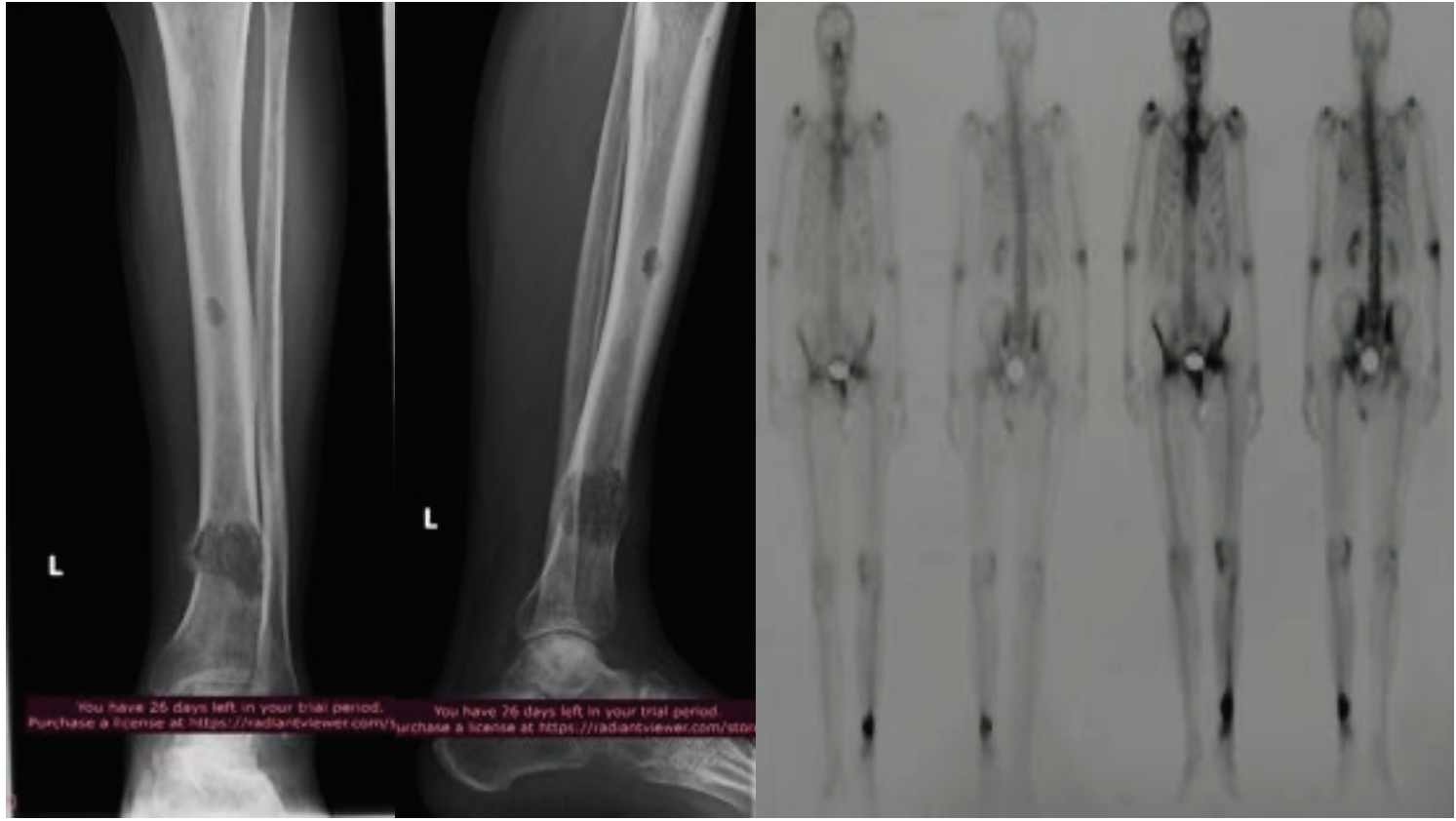

A

B

C

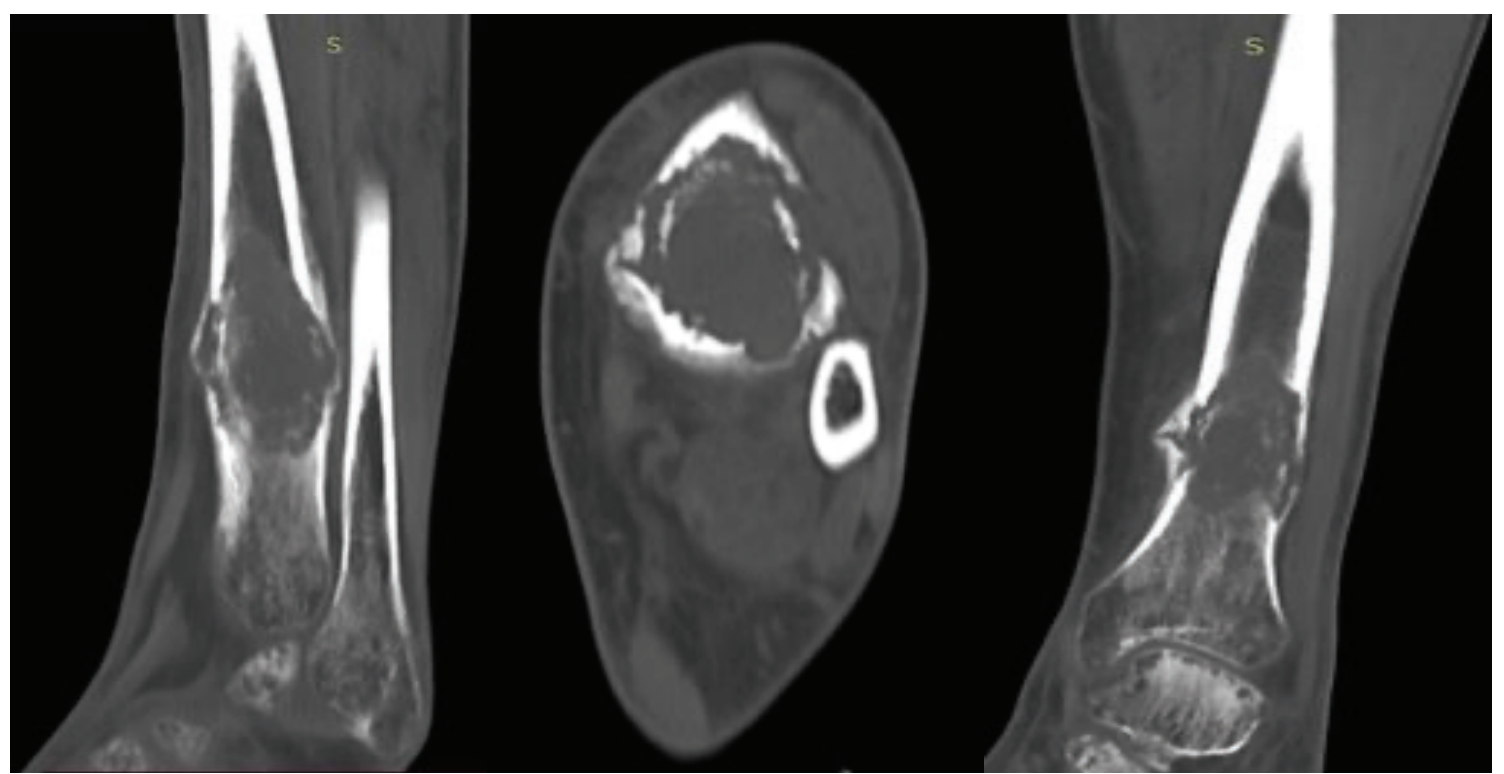

D

E

F

Figure 1. A 62-year-old male with angiosarcoma of distal left tibia. (A) (B) Preoperatively performed X-ray of the affected bone. (C) Whole body bone scan done with Tc99m. (D) (E) (F) CT scan with multiple small slices. Wide resection of $6 \mathrm{~cm}$ long tibial diaphysis segment was made. The defect was reconstructed with intercalary tibial bone allograft and was fixed with two locking plates, thus enabling early mobilization. 


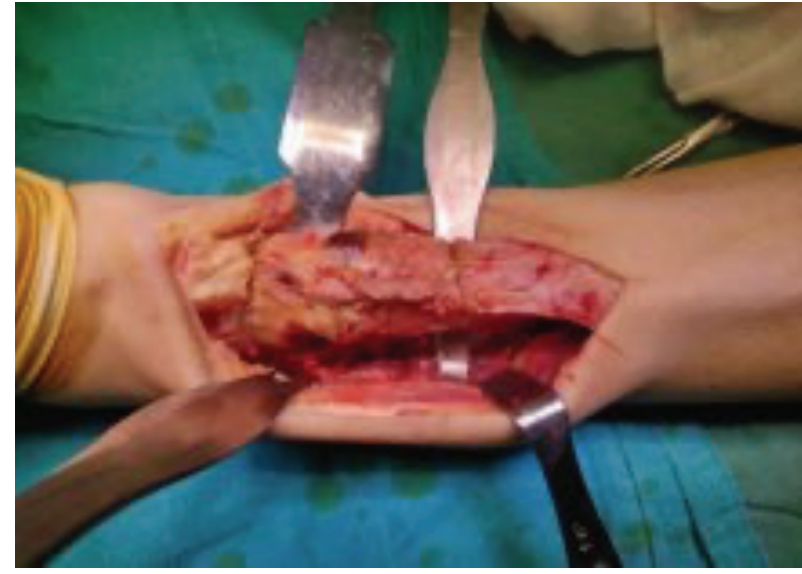

A

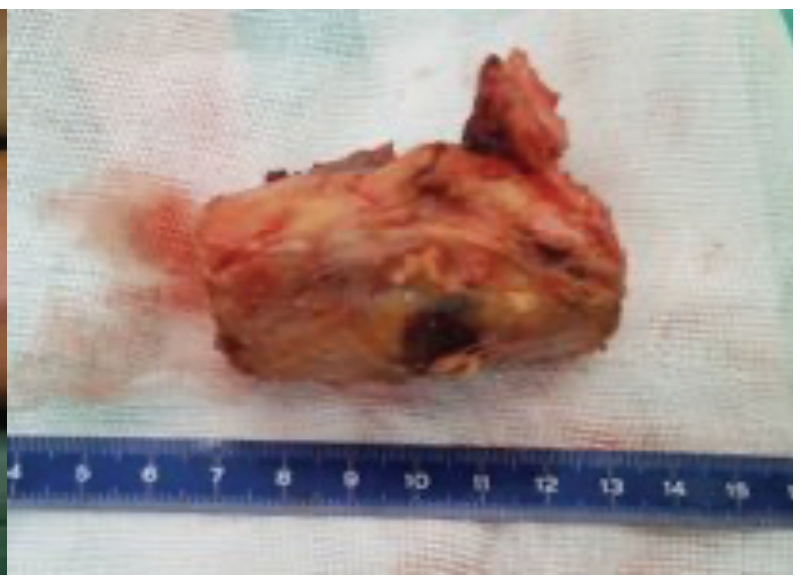

B

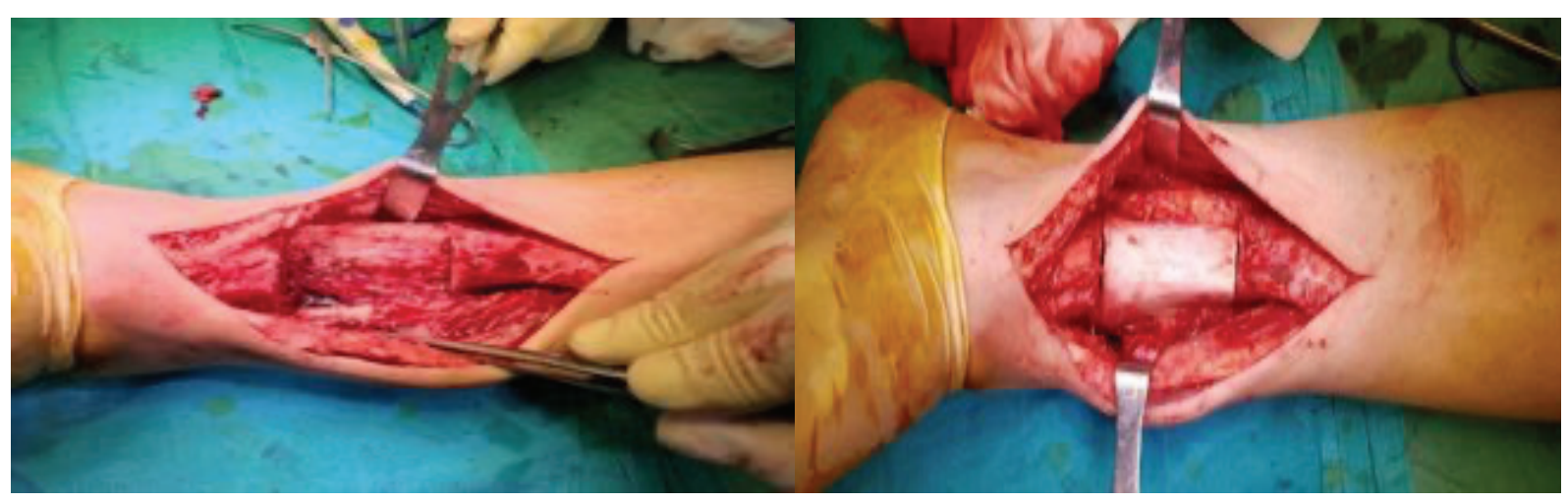

C

D

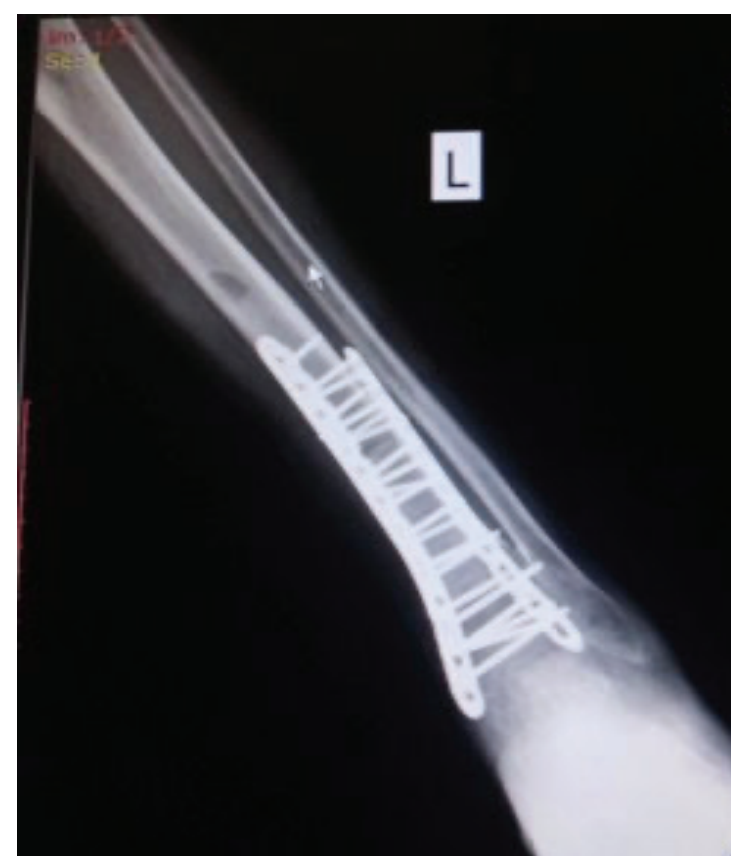

E

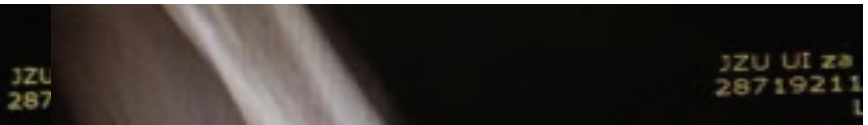

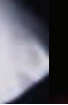

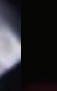

F

Figure 2. Intraoperative samples. (A) Resection of the bone. (B) Measuring the length of the defect. (C) (D) Implantation of a bone from allograft. Osteosynthesis the allograft material with two locking plates. $(E)(F) X$-ray was made 2-nd postoperative day. 


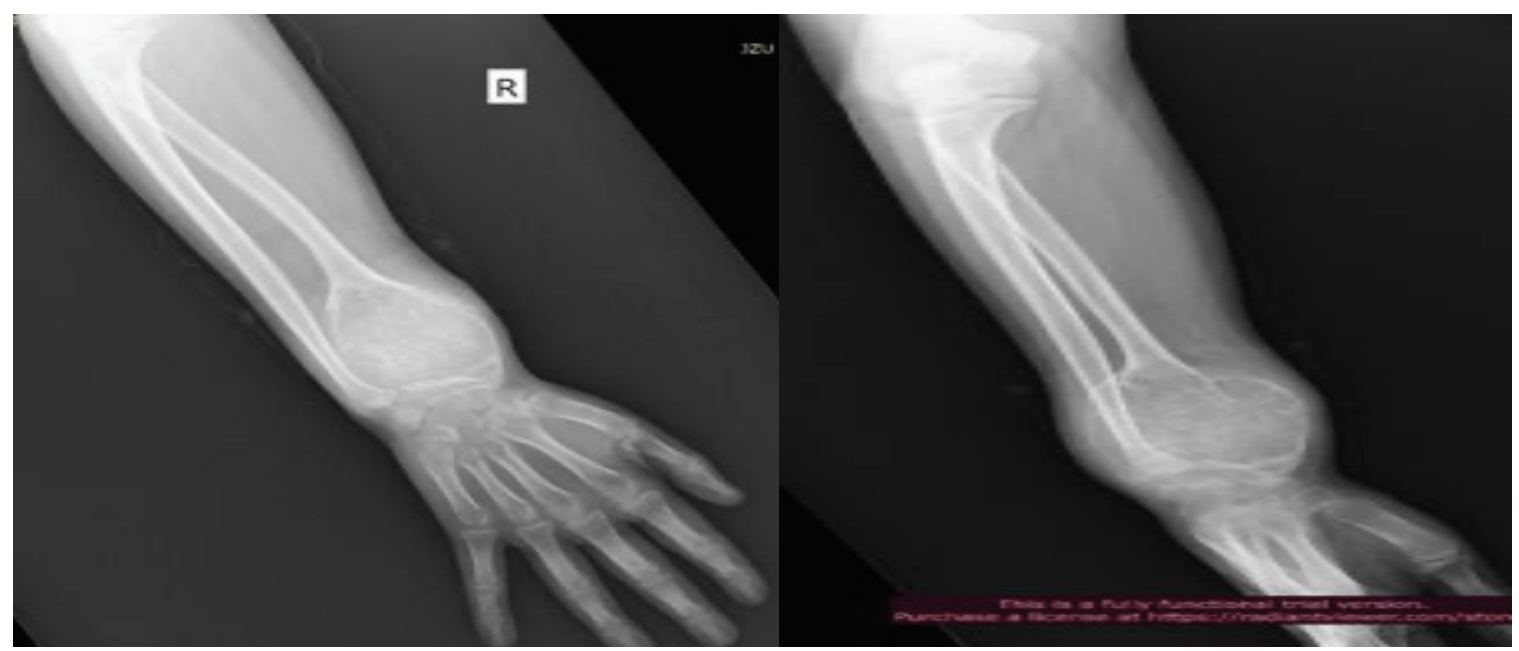

A

B

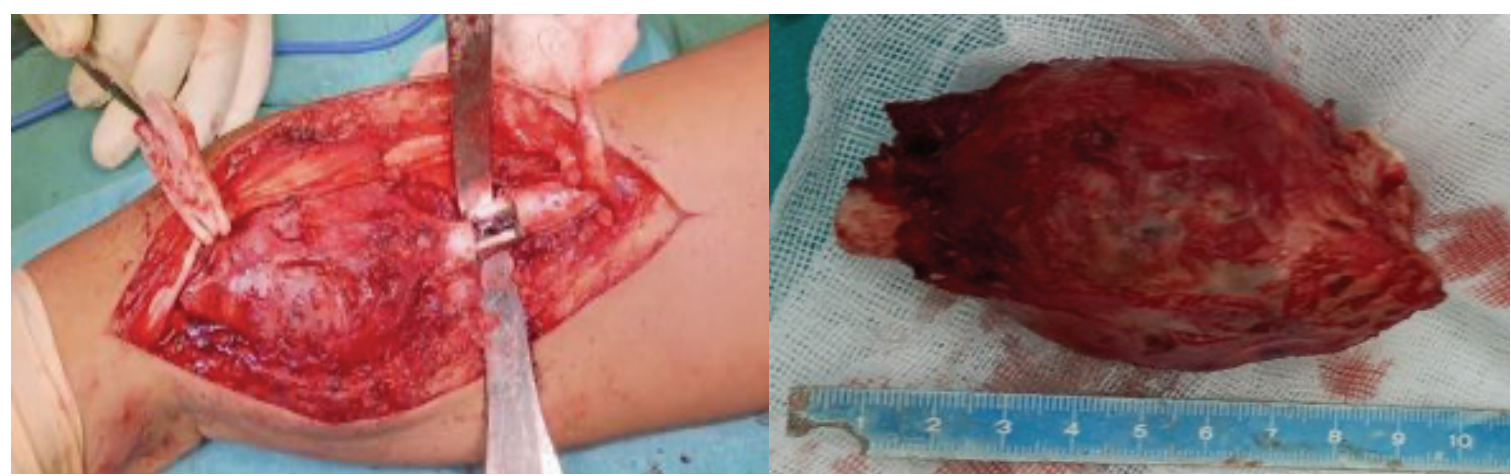

C

D

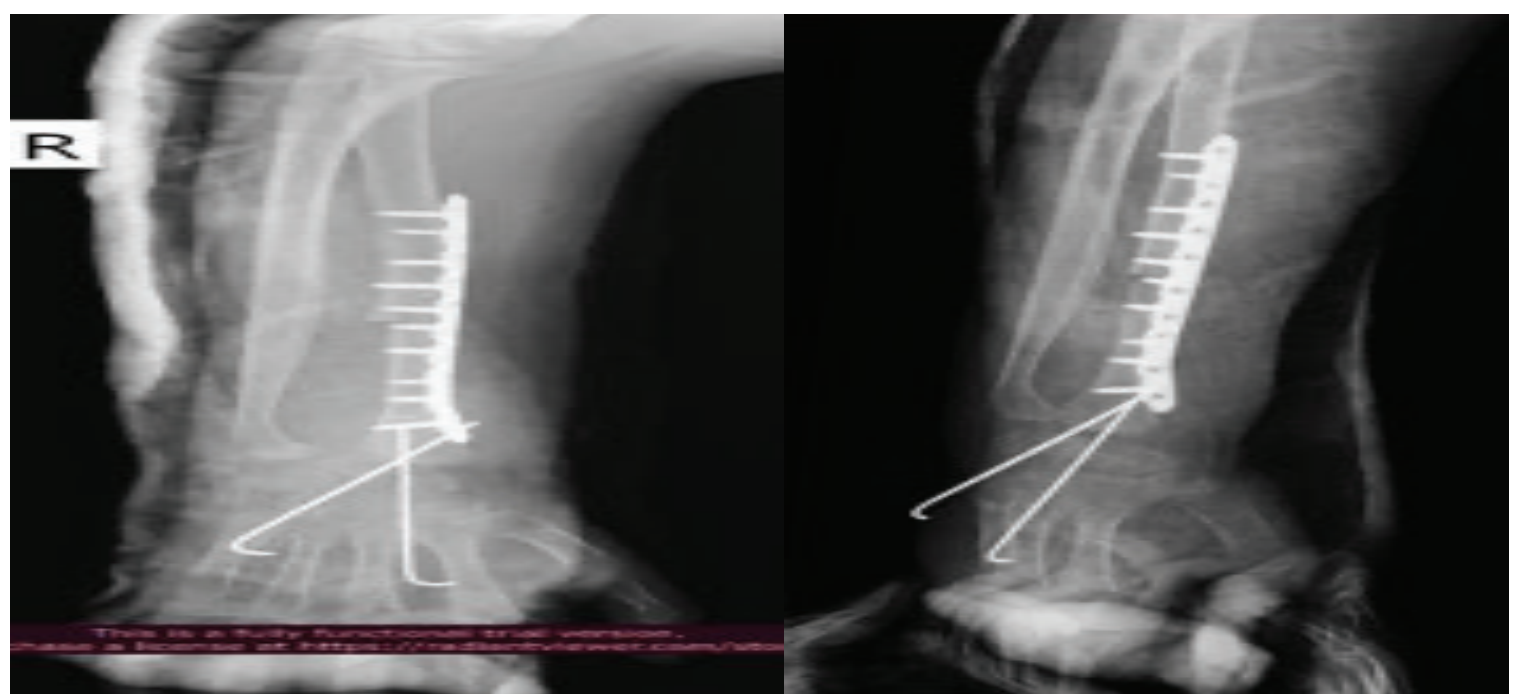

E

F

Figure 3. A 17-year-old male with aggressive giant cell tumor of right radial bone. (A) (B) X-ray of the distal radius and ulna, which revealed an aggressive osteolysis of the right radial bone in her distal part. (C) (D) Distal radius with $7 \mathrm{~cm}$ length, including distal radial articular surface was resected due to joint invasion and fibular cadaveric graft was used. Because the lesion went through the articular surface, radiocarpal joint arthrodesis was performed. (E) (F) X-ray $2^{\text {nd }}$ postoperative day, revealing good position of the osteosynthesis material. 


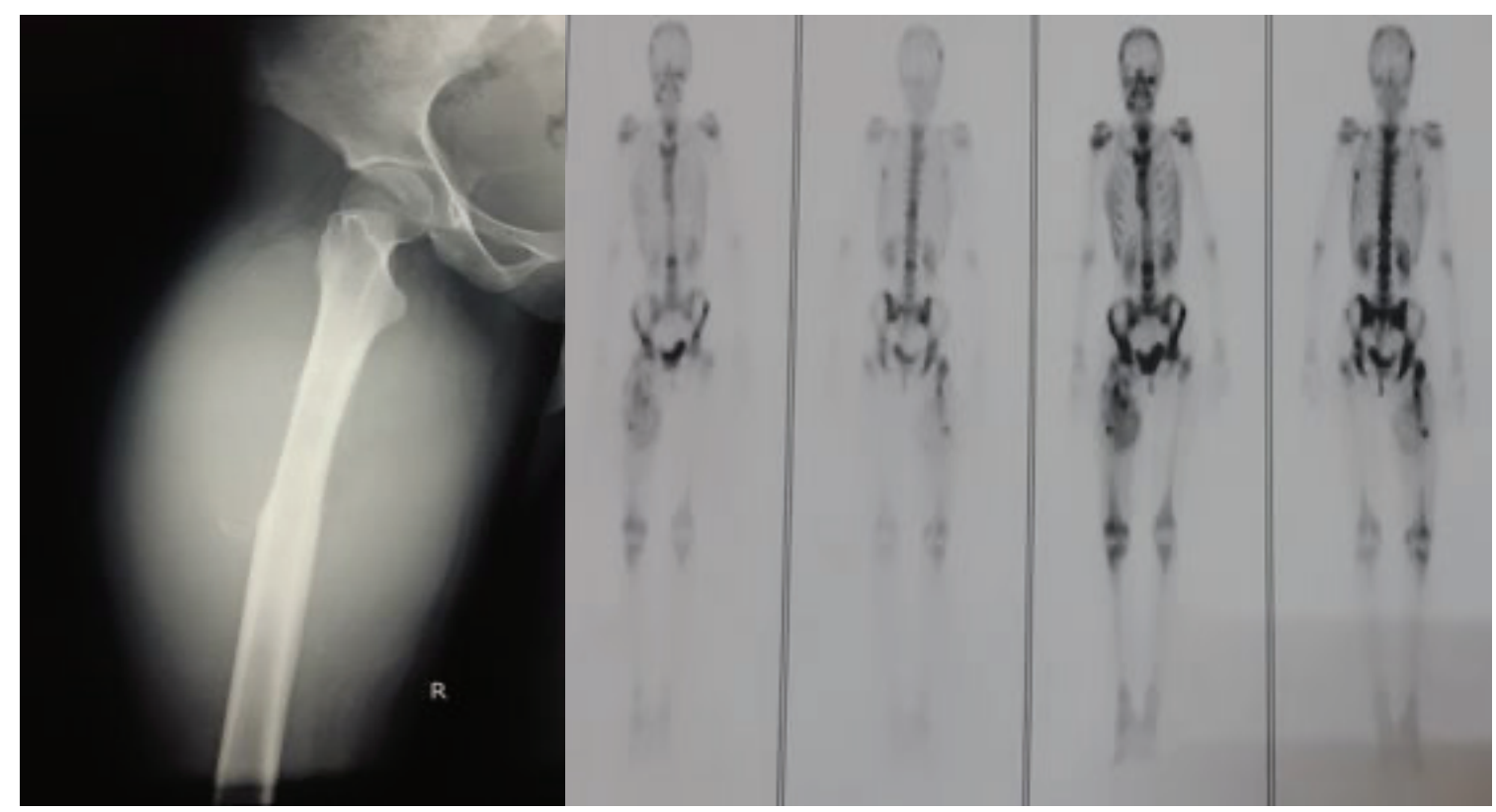

A

B

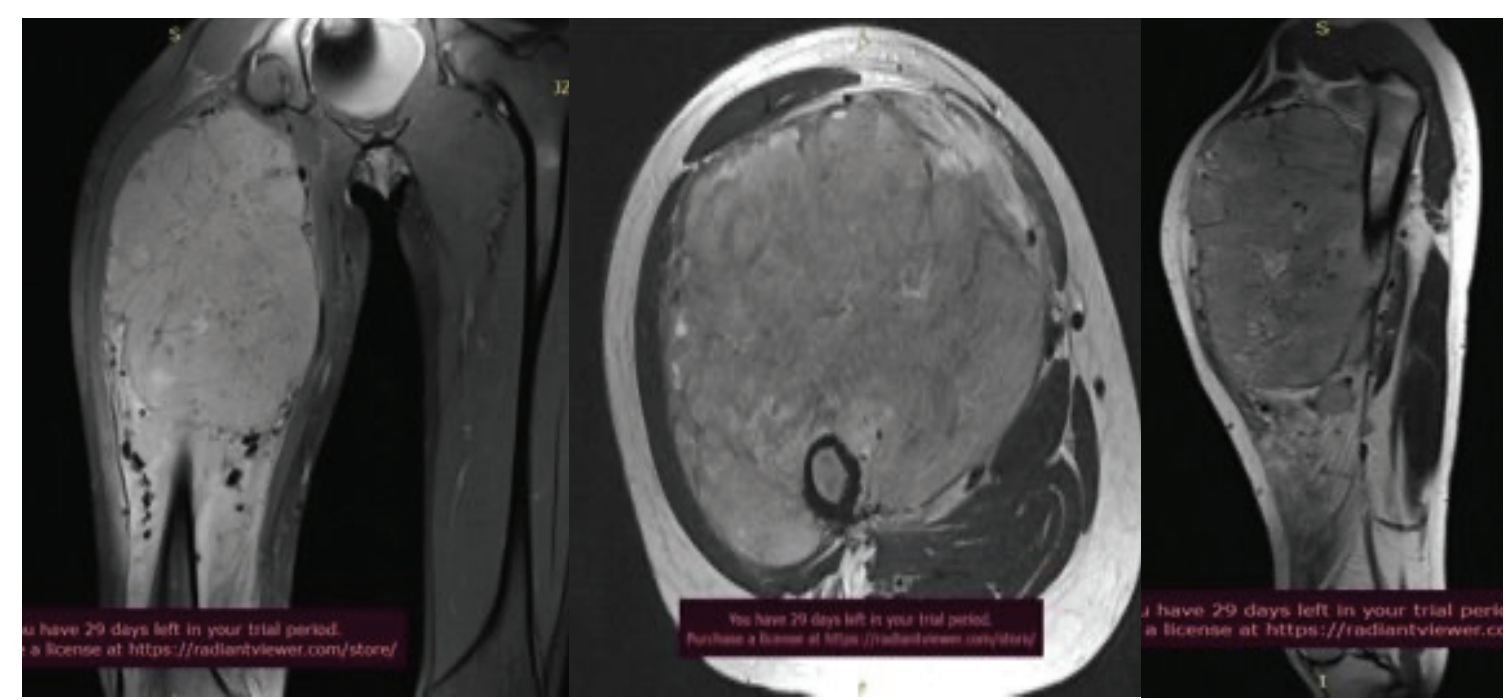

C

D

E

Figure 4. (A) (B) (C) (D) (E) An X-ray and Ct of a 19-year-old female revealed Ewing sarcoma of the proximal part of the right femur, invading the intertrochanteric region and proximal diaphysis. 


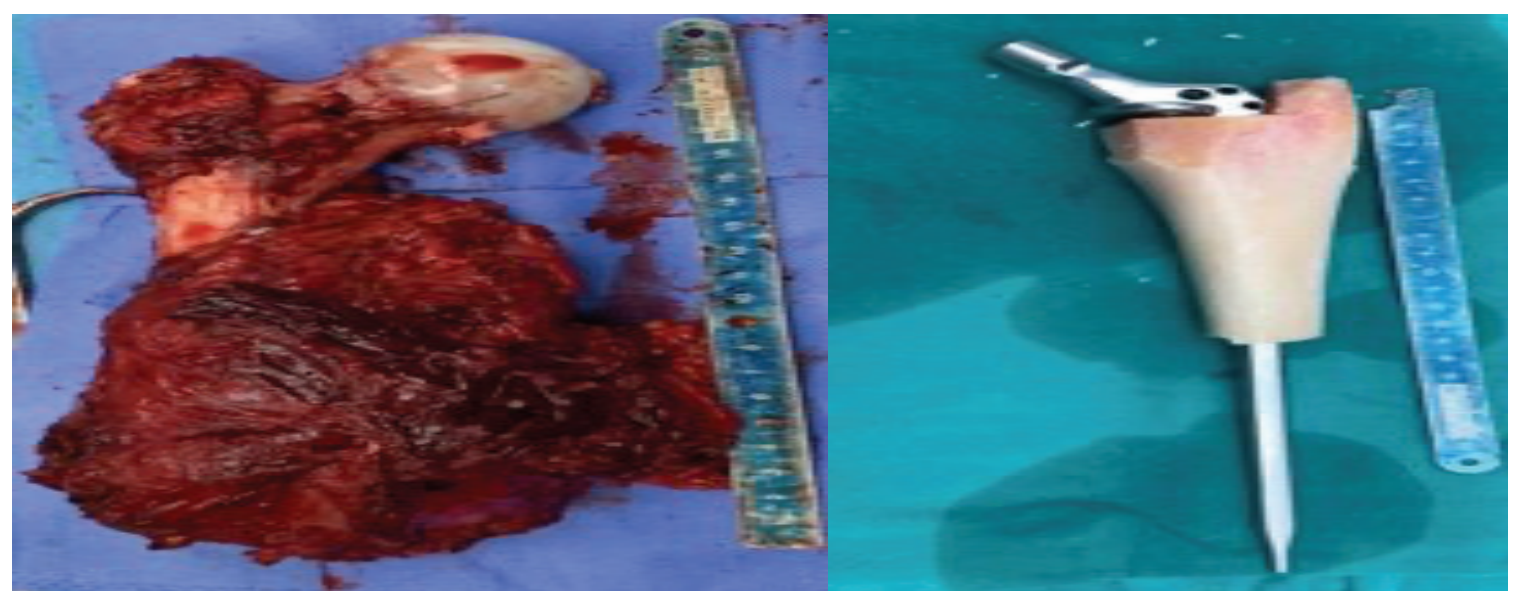

A

B

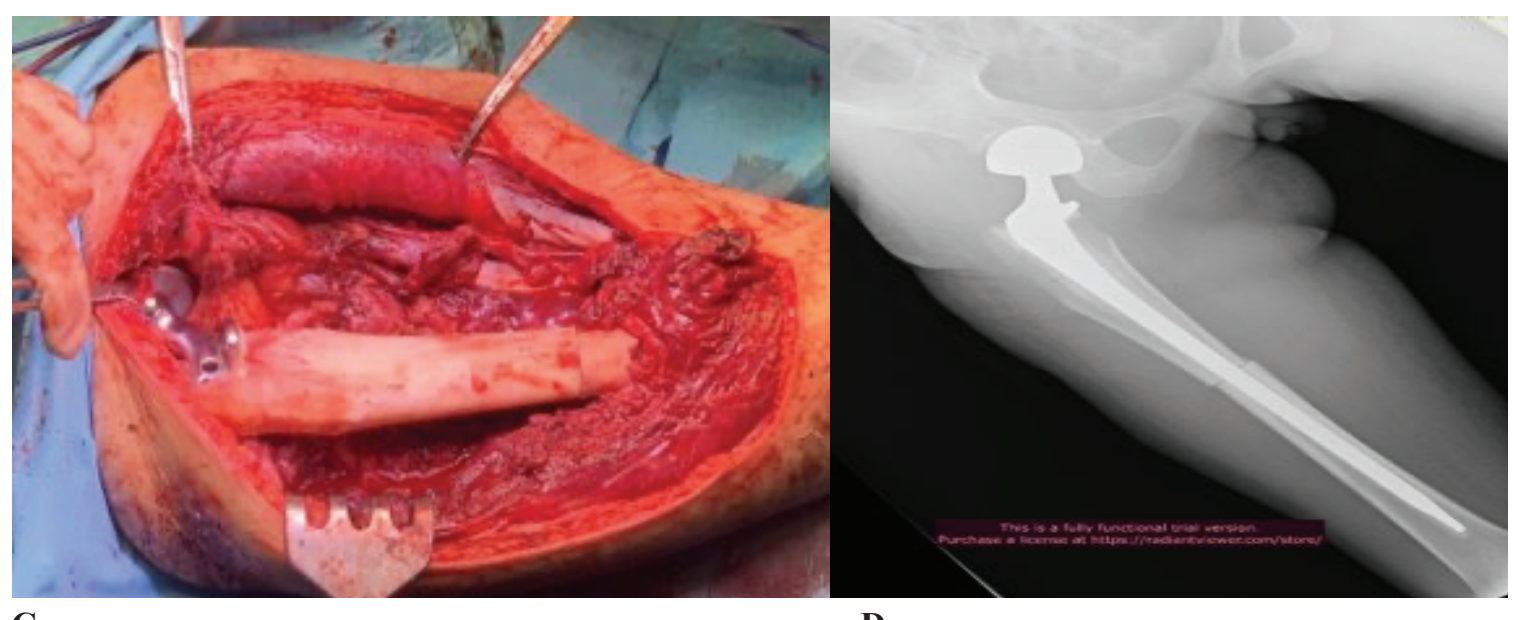

C

D

Figure 5. (A) (B) (C) (D) Resection of proximal femur, application of femoral diaphysis allograft and hip joint endoprosthesis, which allowed for early patient mobilization.

\section{Discussion:}

The standard in bone grafting consists of tissue, harvested from the patient, or autograft, usually the iliac crest or distal femur and proximal tibia. [8] Autologous bone is generally considered as an optimal graft, because it integrates faster, with less complications than any other material. However, autograft sources are limited. For large bone defects and extensive reconstruction, allograft tissue or endoprosthetics devices are therapeutic options, both alone or as a combination. [9] Both techniques carry different advantages and risks for potential complications. Which serves as a better choice?

Cadaveric allograft transplants can aid in reconstruction of large bone defects, including osteoarticular segments by preserving joint function to the largest extent by maintaining articular cartilage and ligaments, and even preserving adjacent growth plates in adolescent patients. [10] There are studies that show that articular cartilage remains viable after cryopreservation, however this cartilage degenerates faster over time and leads to degenerative joint disease. Allografts can fail due to lack of adequate vascularization, that can contribute to inner graft necrosis. [11]

Allogenic bone grafts can also cause immunogenic reactions. Possible complications include: nonunion, infection, resorption and fracture. In a study of 20 patients, treated by resection and osteoarticular allograft application, Ogilvie et al. found high rate of adverse events (70\%) and allograft removal $(60 \%)$ in patients followed for at least 10 years. According to them, although there is high rate of complications and susceptibility to degenerative bone disease as a late complication that threatens function of the graft, there is still a role of osteoarticular allografts in complex reconstructions after tumor surgery. $[5,12]$

Another large study of 398 patients treated with femoral or tibial allografts for low grade sarcomas or highgrade sarcomas responsive to neoadjuvant hemotherapy, showed that risk of allograft removal, joint replacement, or amputation was $36 \%$ at 5 years, $40 \%$ at 10 years, and $44 \%$ at 20 years. In this series, fractures occurred in $15 \%$, infection in $14 \%$, nonunion in $12 \%$ and tumor recurrence 
in $7 \%$ of the patients. The highest grade of graft removal due to complications was observed in the group of tibial osteoarticular allografts. [13]

In a study of 90 patients treated for primary malignant bone tumors by reconstruction with non-vascularized autograft, allograft, and recycled frozen autograft, Wisanuyotin et al. found that there was no difference in functional outcome or complications between the three groups. They recommend that recycled bone should be used for osteoblastic lesions and for extensive osteolytic lesions, the allograft or autograft should be method of choice. [ $\left.{ }^{14}\right]$

Period of highest risk is the first 2 years, as an early complication, and late complications are also being described. In our study, we present cases with short follow up, therefore we cannot analyze late complications of this procedure. [2]

\section{Conclusion:}

Bone tumors should be diagnosed and treated in referral centers by a multidisciplinary team including pathologists, radiologists, orthopedic surgeons and oncologists. There is no prevention. Early diagnosis and adequate treatment are only hope for good outcome.[2]

Biological reconstructions with massive bone allografts are very useful after resection of certain malignant extremity bone tumors. The surgical techniques and method of treatment presented in this report will allow a better functional outcome and quality of life of treated patients. [2]

Our initial experience evocates the obvious advantage of using the allograft for treating lower extremity diaphyseal defect bony reconstruction after tumor resection, but following things should be taken under consideration: [2, 3]

- Precise preparation of allograft;

- Tumor resection for achieving good oncological prognosis post-operative;

- Stable internal fixation;

- Increased surface for bone healing and to prevent bone resorption;

- Adequate soft-tissue coverage;

- Minimizing the risk of post-operative infection and wound dehiscence.

\section{Author Contributions}

$\mathrm{RD}$. conceived and designed the analysis, collected the data, treatment of all the patients in the article, observed the patients, contributed the data and analyses tools, performed the analysis and Interpretations, literature search, wrote the paper, other contributions (take the pictures), supervisor of the project, critical reviewer. IH comprehended and designed the analysis, treatment of all the patients in the article, contributed the data and analyses tools, performed the analysis, wrote the paper, critical reviewer. MM conceived and designed the analysis, collected the data, treatment of all the patients in the article, wrote the paper, other contributions (take the pictures), critical reviewer, literature search. SK, $\mathrm{KGj}$ considered and designed the analysis, collected the data, treatment of all the patients in the article, wrote the paper, other contributions (take the pictures), critical reviewer, literature search

\section{Declaration of any potential financial a nd non-}

\section{financial conflicts of interest:}

The authors declare that they have no known competing financial interests or personal relationships that could have appeared to influence the work reported in this paper.

Ethics approval and consent to participate - all the patients/their parents have signed informed consent.

Consent for photography- all the patients/their parents have signed informed consent

Consent for publication - all the patients/their parents have signed informed consent

Clinical trial registration information provided - not applicable

We confirm that the manuscript, including related data, figures and tables has not been previously published and that the manuscript is not under consideration elsewhere.

\section{References:}

1. Muscolo DL, Ayerza MA, Aponte-Tinao L, Ranalletta M, Abalo E. Intercalary femur and tibia segmental allografts provide an acceptable alternative in reconstructing tumor resections. Clin Orthop Relat Res. 2004;426(426):97-102. doi: 10.1097/01.blo.0000141652.93178.10;

2. Mankin HJ, Gebhardt MC, Jennings LC, Springfield DS, Tomford WW. Long-term results of allograft replacement in the management of bone tumors. Clin Orthop Relat Res. 1996;324(324):86-97. doi: 10.1097/00003086-19960300000011;

3. Aponte-Tinao LA, Ritacco LE, Albergo JI, Ayerza MA, Muscolo DL, Farfalli GL. The principles and applications of fresh frozen allografts to bone and joint reconstruction. Orthop Clin North Am. 2014;45(2):257-269. doi: 10.1016/j. ocl.2013.12.008;

4. Gupta S, Kafchinski LA, Gundle KR, et al. Intercalary allograft augmented with intramedullary cement and plate fixation is a reliable solution after resection of a diaphyseal tumour. Bone Joint J. 2017;99-B(7):973-978. doi: 10.1302/0301-620X.99B7.BJJ-2016-0996;

5. Ogilvie CM, Crawford EA, Hosalkar HS, King JJ, Lackman RD. Long-term results for limb salvage with osteoarticular allograft reconstruction. Clin Orthop Relat Res. 2009;467(10):2685-2690. doi:10.1007/s11999-009-0726-9;

6. Enneking WF, Campanacci DA. Retrieved human allografts: a clinicopathological study. $J$ Bone Joint Surg Am. 2001;83(7):971-986. doi:10.2106/00004623-20010700000001 ;

7. Mankin HJ, Hornicek FJ, Raskin KA, Infection in massive bone allografts. Clin Orthop Relat Res. 2005;(432):210-216. doi: 10.1097/01.blo.0000150371.77314.52; 
8. Bus MP, Dijkstra PD, van de Sande MA, et al. Intercalary allograft reconstructions following resection of primary bone tumors: a nationwide multicenter study. J Bone Joint Surg Am. 2014;96(4): e26. doi:10.2106/JBJS.M.00655;

9. GLASSER D, LANGLAIS F. The ISOLS Radiological Implants Evaluation System. In Limb Salvage: Major Reconstructions in Oncologic and Nontumoral Conditions. Berlin: Springer-Verlag; 1991;

10. Enneking WF, Dunham W, Gebhardt MC, Malawar M, Pritchard DJ. A system for the functional evaluation of reconstructive procedures after surgical treatment of tumors of the musculoskeletal system. Clin Orthop Relat Res. 1993;(286):241-246;

11. Bus MP, Dijkstra PD, van de Sande MA, et al. Intercalary allograft reconstructions following resection of primary bone tumors: a nationwide multicenter study. J Bone Joint Surg Am. 2014;96(4): e26. doi:10.2106/JBJS.M.00655;
12. Qu H, Guo W, Yang R, et al. Reconstruction of segmental bone defect of long bones after tumor resection by devitalized tumor-bearing bone. World J Surg Oncol. 2015;13(1):282. doi: 10.1186/s12957-015-0694-3;

13. Aponte-Tinao LA, Ayerza MA, Albergo JI, Farfalli GL. Do Massive Allograft Reconstructions for Tumors of the Femur and Tibia Survive 10 or More Years after Implantation? Clin Orthop Relat Res. 2020;478(3):517-524. doi:10.1097/ CORR.0000000000000806

14. Wisanuyotin T, Paholpak P, Sirichativapee W, Kosuwon W. Risk factors and outcomes for failure of biological reconstruction after resection of primary malignant bone tumors in the extremities. Sci Rep. 2021;11(1):20444. Published 2021 Oct 14. doi:10.1038/s41598-021-00092-1 